\title{
Vibration Response Imaging in medical-surgical ICU
}

\author{
JOSIP ŽUNIĆ ${ }^{1,2}$, MATIJA BELAVIĆ ${ }^{1}$, MIRJANA LONČARIĆ-KATUŠIN ${ }^{l}$ \\ ${ }^{1}$ Department of Anaesthesiology, Reanimatology and Intensive Care, General Hospital \\ Karlovac, 47000 Karlovac, Croatia \\ ${ }^{2}$ Karlovac University of Applied Sciences, 47000 Karlovac, Croatia
}

Corresponding author:

Josip Žunić

Karlovac General Hospital, Andrije Štampara 3, 47000 Karlovac, Croatia

Phone: +38547608329 , Fax: +38547608311 ,

E-mail: jzvuka@gmail.com

\section{ABSTRACT}

The new method of monitoring lung function ("vibration response imaging"- VRI) converts vibration energy that appears in the bronchial tree during airflow into an image. The VRI does not use energy that could have a detrimental effect on the cells and organs. The goal of our research was to verify the VRI device in the diagnosis and the localization of various lung pathologies. In our medical-surgical ICU we did a retrospective analysis of the prospective database that included 61 patients. We compare VRI with chest X-ray and CT scan in patients with intrathoracic (the presence of air and fluid in the intrapleural space, pulmonary hypoventilation, atelectasis, contusion and inflammatory lung pathology) or extrathoracic pathology that affect respiratory function.

Intrathoracic pathology was observed in 32 patients and extrathoracic pathology in 29 patients. The use of the VRI device showed earlier disorder of hypoventilation compared to chest X-ray, especially after abdominal surgical procedures, intraabdominal hypertension and various lung pathology as it detected laterobasal pneumothorax earlier.

In our patients VRI has been proven to be a reliable method for detecting regional distribution of ventilation and atelectasis of the lungs of individual parts regardless of pulmonary pathology. VRI is shown as a reliable method for detecting air and fluid in the intrapleural space.

Key words: Vibration response imaging, lung, ventilation

\section{INTRODUCTION}

Examination of the lungs is based on clinical methods (auscultation and percussion) and paraclinical methods (chest X-ray, CT scan, lung ultrasound). Chest radiograph remains the simplest, most efficient and routinely available method to assess the status of the lung parenchyma in ICU. Its shortcoming is that it only gives an estimate of the general severity of the disease. CT scan provides more specific and detailed information, but patients need to be transferred to scanning suites. Transportation may be associated with increased mortality of patients. Lung ultrasound is a non-invasive, easily repeatable method which effectively assesses pleural effusion, pneumothorax, alveolar-interstitial syndrome, lung consolidation, pulmonary abscess and lung recruitment/derecruitment at the bedside. Modern methods such as VRI and electrical bioimpedance tomography (EIT) are cheap, non-invasive, allow continuous monitoring of ventilation at the bedside and do not emit radiation. (1-2) VRI and EIT provide bedside assessment of regional lung function and thereby allow us to optimize therapy.

The goal of our research was to verify the VRI device in the diagnosis of various lung pathologies and assessment distribution of regional ventilation patients in medicalsurgical ICU.

\section{MATERIALS AND METHODS}

The clinical investigation with the VRI device was prior approved by the Ethics Committee of General Hospital Karlovac. We conducted a retrospective analysis of the prospective database that included 61 patients in the general intensive care unit. We used the VRI device in patients with intrathoracic and extrathoracic pathology and in patients with spontaneous breathing or mechanical ventilation. We divided intrathoracic pathology into the pathology of lungs (lung parenchyma and pulmonary vessels) and pathology of pleural space (hydrothorax, hematothorax or pneumothorax). Extrathoracic pathology was divided into the pathology of other organ systems and surgical procedures (especially abdominal) that affect the respiratory function. For example, intraabdominal hypertension and congestive heart failure affect respiratory function. We compared the images provided by the VRI device with the chest X-ray and MSCT images. We also used descriptive statistics for anthropometric description of subjects that were examined.

\section{The VRI device}

The VRI device shows qualitative and quantitative distribution of lung sounds and it converts to dynamic images during both the inspiratory and the expiratory phase. (3) Respiratory sounds are the result of turbulences generated during the flow of air in large and medium airways when the air flow reaches critical speed. The intensity of vibrations can vary in frequency, intensity and duration. Vibration signals are detected by piezoelectric sensors that are attached on both sides of the patient's back. Signals are processed using a special VRI software and appear as dynamic lung image. With the VRI device we can freeze images at a certain time point, record data and analyse multiple sequences of recorded images.

\section{Description of the recording procedures}

The recordings were made in the sitting position and lying position. The recording lasted for 20 seconds and the examinee was breathing deeply with a frequency of 18-24 
per minute. At least three recordings were made for each patient. During the recording all examiners and staff in the ICU were quiet. The lung sounds were processed by the VRI software that converts breathing sounds into a dynamic lung image. The software also displayed quantitative assessment of breathing sound distribution.

\section{RESULTS}

We applied the VRI device to a total of 61 patients in our ICU (table 1). There were 37 men and 24 women. Of the 61 patients 43 breathed spontaneously (70.49\%) and 18 had been subjected to mechanical ventilation. Table 2. shows the distribution of the patients who underwent the VRI examination: 32 (52.5\%) with intrathoracic pathology and 29 (47.5\%) with extrathoracic pathology. The use of the VRI device showed earlier disorder of ventilation then when using clinical methods and chest X-ray especially after the upper abdominal surgical procedures. The VRI device showed the postoperative regional distribution of ventilation - hypoventilation of the basal parts of the lungs. In a case with serial fractures from the fifth to the eighth rib with laterobasal pneumothorax we could not make a diagnosis by using conventional radiological methods first, only by using the VRI device. By using VRI we could monitor therapeutic effects during NIV and mechanical ventilation. By watching the image on the VRI monitor we could relatively easily determine the best PEEP and predict a successful extubation. In some tachydyspneic patients that were breathing spontaneously the VRI device could not record images because the intensity of breathing sounds was too strong for recording. It is a disadvantage that some pathologies such as pulmonary embolism cannot be seen with VRI. Other pathologies of lung parenchyma or intrapleural space are well-observed by VRI.

Vibration response imaging snapshot shows hypoventilated right lung towards left lung in dynamic image and quantitative lung data shows right lung hypoventilation of $21 \%$ compared to left lung of $79 \%$. Hypoventilated right lower lobe of $4 \%$ towards left lower lobe of $33 \%$. This finding correlates with X-ray image.
Table 1. Descriptive statistics $(\mathrm{N}=61)$

\begin{tabular}{lll}
\hline Statistics & Age & Weight \\
\hline Minimum: & 18 & 52 \\
\hline Maximum: & 88 & 167 \\
\hline Mean \pm SD: & $61.75 \pm 18.31$ & $73.22 \pm 16.19$ \\
\hline Median: & 69 & 71 \\
\hline & & \\
\hline
\end{tabular}

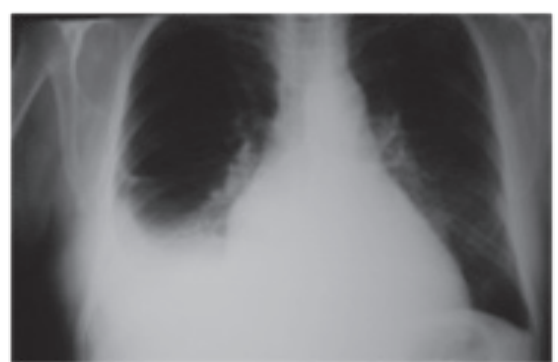

\begin{tabular}{c|c|c|}
\cline { 2 - 3 } \multicolumn{1}{c|}{ Upper } & Pight & Left \\
\hline Middle & $5 \%$ & $15 \%$ \\
\hline \multirow{2}{*}{ Lower } & $12 \%$ & $31 \%$ \\
\hline Total & $4 \% 6$ & $33 \%$ \\
\cline { 2 - 3 } & 2196 & $79 \%$ \\
\hline
\end{tabular}

Figure 1. Pathology of pleural space: right sided liquidothorax

\section{DISCUSSION}

In the group of the patients we examined, we have noticed that the VRI device at the bedside showed dynamic images (changes) of lungs whereas X-ray and CT scans show (only) the anatomy (structure) of the respiratory tract. In patients with COPD who are mechanically ventilated the VRI recording is different from the VRI recording in patients that are mechanically ventilated but do not have COPD. It is possible to see the qualitative and quantitative differences between patients with COPD or asthma. (4) By using VRI we can assess the performance of therapeutic procedures such as administering bronchodilators in the treatment of bronchospasm or monitoring the improvement of ventilation after bronchoscopy. $(4,5)$ The VRI's sensitivity and specificity of large airway obstruction is $97 \%$ and $88 \%$. (5) The VRI device is precise in diagnosing a pneumothorax, because the appearance of the VRI image and the reduction of vibration energy in quantitative lung data (QLD) correlate with X-ray images (sensitivity $100 \%$, specificity $87 \%$ ). (6). It is also a reliable method in the diagnosis of pleural effusions because of the high sensitivity of the method that is $86 \%$, specificity of $93 \%$, positive predictive value of $95 \%$ and negative predictive value of 79\%. (7) In patients with unilateral lung pathology the changes were more significant on the affected side of the lungs.

The use of the VRI in different modalities of ventilation shows that pressure support ventilation, and to a lesser extent pressure controlled ventilation, cause shifts of vibration towards lower lung fields, as opposed to VCV with the same respiratory volume. (8) The use of VRI in mechanically ventilated patients with increasing values of PEEP showed a significant redistribution of the vibrations towards basal lung parts, regardless of the support required with the ventilator. (9) The VRI device is especially useful in patients with ARDS, where an accurate titration of PEEP is important for better ventilation and oxygenation as well as to reduce lung injury. (10) The VRI is also an effective method for assessing the effectiveness of recruitment manoeuvres and PEEP values set in acute lung injury. Decreased vibration energy in the VRI recordings following effective recruitment has an inverse correlation with the improvement of compliance and oxygenation, suggesting that a greater volume of open lung at the start of inspiration may be associated with less 
vibration during the inspiration phase of ventilation. A decrease in the opening of atelectatic lung and the associated decrease in vibration energy during the early period of inspiration may be the explanation for this finding. The percentage increase in spatial distribution of ventilation as measured by VRI may be a useful parameter in predicting successful extubation.

\section{CONCLUSION}

VRI is a new non-invasive diagnostic method, which does not emit radiation and is a cheaper diagnostic tool than the conventional methods. In our research we wanted to verify its effectiveness. The VRI device provides valuable insight into ventilation of various lung parts during the monitoring of pleural pathologies and lung pathologies. VRI is a promising non-invasive tool for evaluating the initial therapeutic effects of NPPV and mechanical ventilation.

Its place is not only in intensive care medicine, but in other units as well where we try to observe the pathological changes that affect lung ventilation.

Table 2. Classification of respondents into healthy respondents and those with intrathoracic and extrathoracic pathology

\begin{tabular}{|c|c|c|c|c|}
\hline \multirow{11}{*}{$\begin{array}{l}\text { Pathology } \\
\mathrm{N}=61\end{array}$} & \multirow{8}{*}{$\begin{array}{l}\text { Intrathoracic } \\
\mathrm{N}=32(52,5 \%)\end{array}$} & \multirow{4}{*}{$\begin{array}{l}\text { Lungs } \\
\mathrm{N}=19\end{array}$} & $\begin{array}{l}\text { Pulmonary vessels } \\
\mathrm{N}=13\end{array}$ & Embolism \\
\hline & & & \multirow{3}{*}{$\begin{array}{l}\text { Parenchyma } \\
\mathrm{N}=6\end{array}$} & $\begin{array}{l}\text { Trauma } \\
\mathrm{N}=3\end{array}$ \\
\hline & & & & $\begin{array}{l}\text { Inflammation } \\
\mathrm{N}=2\end{array}$ \\
\hline & & & & $\begin{array}{l}\text { Tumor } \\
\mathrm{N}=1\end{array}$ \\
\hline & & \multirow{4}{*}{$\begin{array}{l}\text { Pleural space } \\
\mathrm{N}=13\end{array}$} & & $\begin{array}{l}\text { Pneumothorax } \\
\mathrm{N}=5\end{array}$ \\
\hline & & & & $\begin{array}{l}\text { Liquidothorax } \\
\mathrm{N}=5\end{array}$ \\
\hline & & & & $\begin{array}{l}\text { Pneumoliquidothorax } \\
\mathrm{N}=2\end{array}$ \\
\hline & & & & $\begin{array}{l}\text { Fibrothorax } \\
N=1\end{array}$ \\
\hline & \multirow{3}{*}{$\begin{array}{l}\text { Extrathoracic } \\
N=29(47,5 \%)\end{array}$} & \multicolumn{3}{|c|}{$\begin{array}{l}\text { Intraabdominal hypertension } \\
\text { (ascites, ac. pancreatitis) } \\
\mathrm{N}=3\end{array}$} \\
\hline & & \multicolumn{3}{|c|}{$\begin{array}{l}\text { Congestive heart failure } \\
\mathrm{N}=6\end{array}$} \\
\hline & & \multicolumn{3}{|c|}{$\begin{array}{l}\text { Pathology of other organ systems and surgical procedures (especially abdominal) that affect the } \\
\text { respiratory function } \\
\mathrm{N}=20\end{array}$} \\
\hline
\end{tabular}

\section{REFERENCES}

1. Costa ELV, Lima RG, Amato MBP. Electrical impedance tomography. Curr Opin Crit Care 2009;15:18-24.

2. Becker DH: Vibration response imaging - finally a real stetoscope. Respiration 2009;77:236-239.

3. Dellinger RP, Parrillo JE, Kushnir A, Rossi M, Kushnir I. Dynamic Visualization of lung sounds with a vibration response device: A case series. Respiration 2008;75:60-72.

4. Guntupalli KK, Reddy RM, Loutfi RH, Alapat PM, Bandi VD, Hanania NA. Evaluation of obstructive lung disease with vibration response imaging. J Asthma 2008;45:923-930.

5. Becker HD, Slawik M, Miyazawa T, Gat M. Vibration response imaging as a new tool for interventional-bronchoscopy outcome assessment: a prospective pilot study. Respiration 2009;77:179-194.

6. Blanco M, Mor R, Fraticelli A, Breen DP, Dutau H. Distribution of breath sound images in patients with peumothoraces compared to healthy subjects. Respiration 2009; 77:173-178.

7. Anantham D, Herth FJ, Majid A, Michaud G, Ernst A. Vibration response imaging in the detection of pleural effusions: a feasibility study. Respiration 2009;77:166-72.

8. Dellinger RP, Jean S, Cinel I, Tay C, Rajanala S, Glickman YA, Parrillo JE. Regional distribution of acoustic-based lung vibration as a function of 
mechanical ventilation mode. Crit Care 2007;11(1):R26.

9. Lev S, Glickman YA, Kagan I, Dahan D, Cohen J, Grinev M, Shapiro M, Singer P. Changes in regional distribution of lung sounds as a function of positive end-expiratory pressure. Crit Care 2009;13(3):R66.

10. Trivedi H, Cinel I, Jean S, Tay C, Durflinger P, Parrillo JE, Dellinger RP. The role of vibration response imaging in the titration of PEEP in a mechanically ventilated patient with acute respiratory distress syndrome. Crit Care Med 2006;34(12):A170. 